IJHER International Journal of Humanities and Educational Research ISSN: 2757-5403

Volume 4, Issue 1, February 2022

Received: 02/01/2022

Accepted: $17 / 01 / 2022$

Published: 01/02/2022

\title{
ASSESSMENT AND EVALUATING THE KNOWLEDGE OF A SAMPLE OF PRIMARY SCHOOL TEACHERS ON SAFETY MEASURES AND FIRST AID IN THE SCHOOL ENVIRONMENT (FIELD STUDY)
}

\author{
Ateka Fakhari KHAIRULLAH 1 \\ Dr, Middle Technical University, Iraq
}

\begin{abstract}
The current research aims to evaluate the knowledge of a sample of primary school teachers from different disciplines in The City of Baghdad, where the size of the random research sample (50 teachers) distributed on both sides of al-Karkh and Al-Rasafa, About safety measures and first aid and their role in implementing those measures and carrying out first aid for students in the event of accidents within the school environment and then arranging the transfer of the injured person to the nearest hospital within the geographical area of the school, The aim of the research was also to evaluate that knowledge by making recommendations and suggestions.

The descriptive analytical method of the research sample vocabulary was adopted using the resolution tool that set its questions to achieve the above-mentioned research objectives. Hence the scheduling and presentation of research data and the adoption of the percentage as a statistical means of research and then presenting the findings and conclusions followed by a review of the most important recommendations and proposals that may contribute to raising the efficiency and role of primary school teachers in the field of health, safety and accident prevention, as well as early detection of infection swells among pupils, Finally, the research was appendixed to the most important sources used, which were used to record search information.
\end{abstract}

Key words: Assessment, Evaluation, First Aid, Primary School, School Health, Preventive Medicine.

http://dx.doi.org/10.47832/2757-5403.12.14

1(

atekaf54@gmail.com https://orcid.org/0000-0002-4851-3337

www.ijherjournal.com 


\title{
تقييم وتقويم معارف عينة من معلمي المرحلة الابتدائية حول إجراعات السلامة والإسعاف الأوّلي في بيئة المدرسة (دراسة ميدانية)
}

\author{
عاتكة فخري خير الله \\ د ، الجامعة التقنبة التوسطى، فير، العراق
}

\begin{abstract}
الملخص
يهوف البحث الحالي إلى تقييم معارف عينة عشو ائية من معلمي المرحلة الابتدائية من مختلف التخصّصات في مدينة بغداد

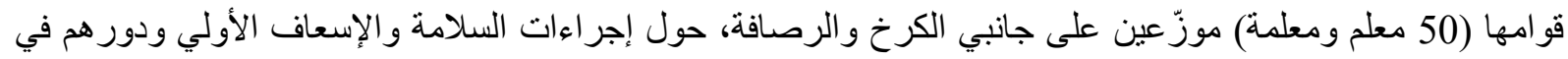

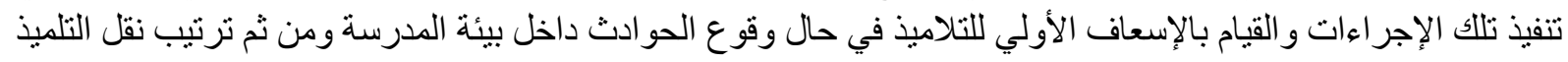

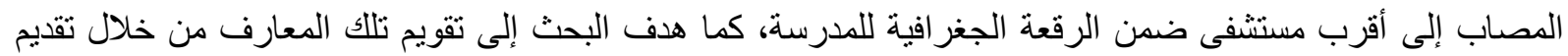
التوصيات و المقترحات.

تمّ اعتماد المنهج الوصفي التحليلي لمفردات عينة البحث باستخدام أداة الاستبانة التي وضعت أسئلتها لتحقّق أهداف البحتث

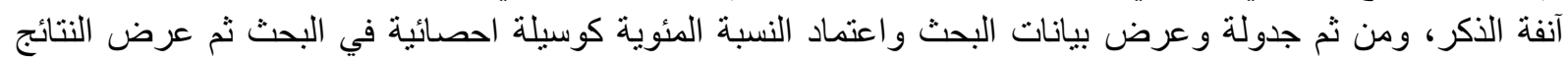

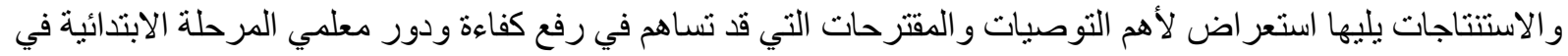

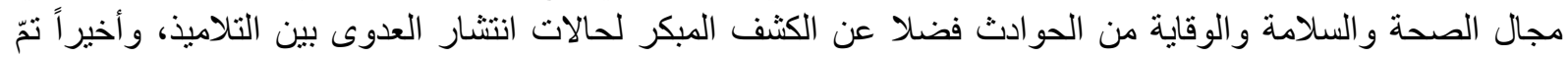

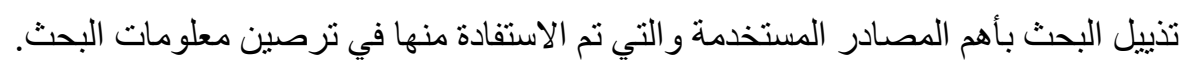

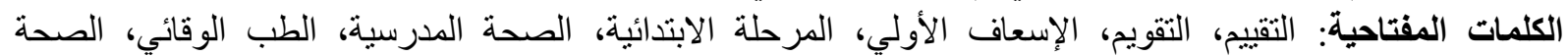

المقدمة:

يقضي التلاميذ في المدرسة وقتا يمتد بين 5 - 8 ساعات يوميا يتلقى خلالها مختلف المعارف التعليمية العلمية

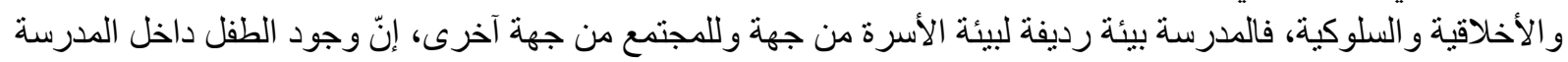

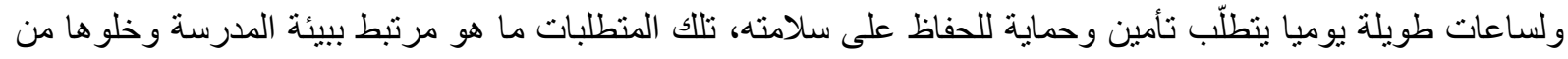

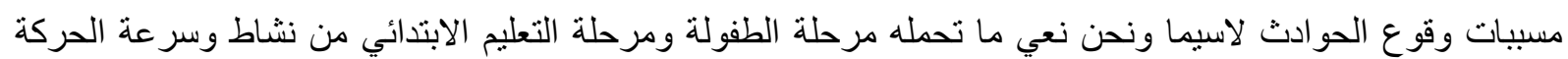

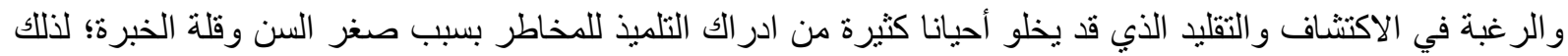

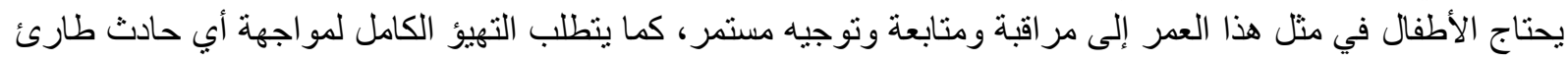

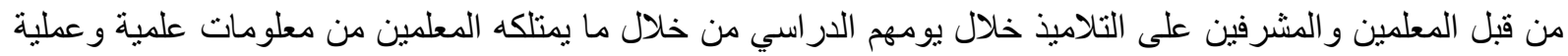

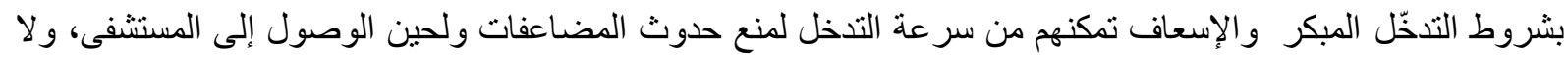

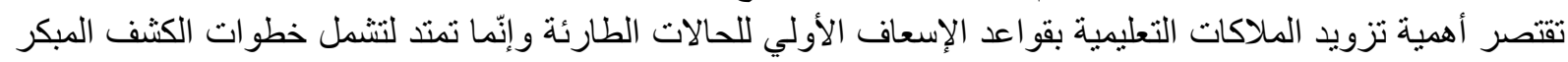

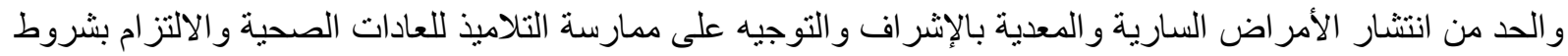

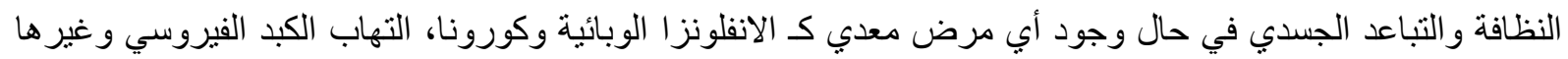

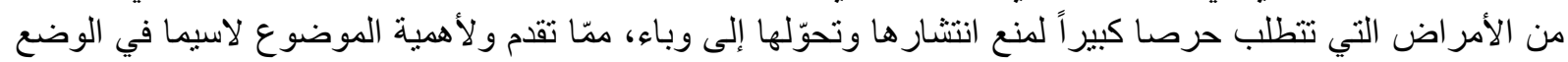

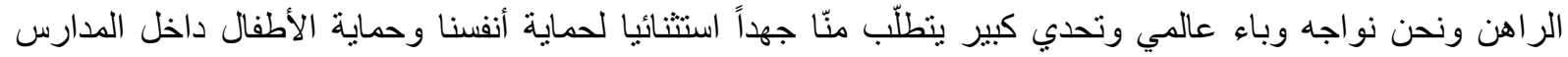

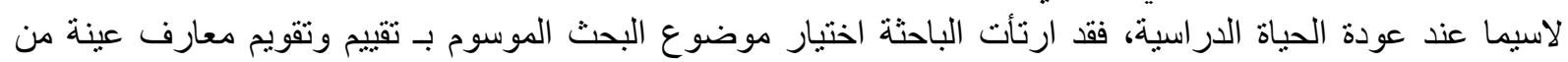

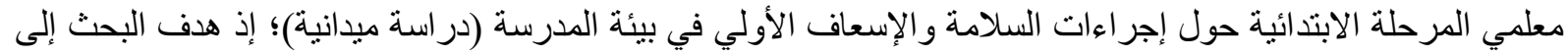

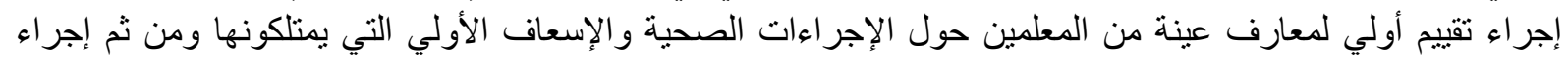

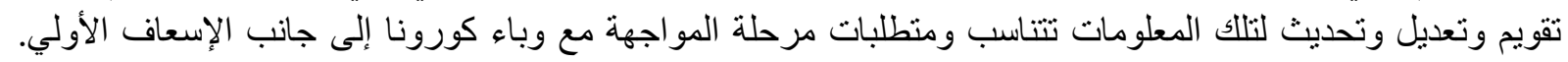

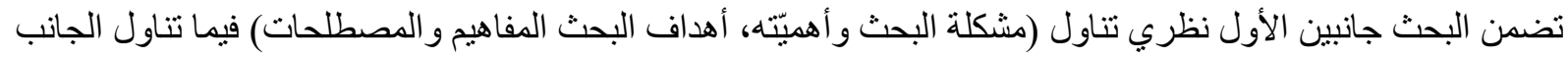

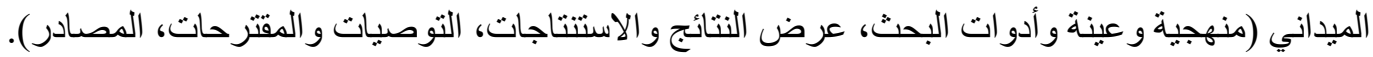


الجانب النظري: (مشكلة البحث وأهميته، أهداف البحث المفاهيم والمصطلحات) مشكلة البحث وأهميته:

ترتبط مشكلة البحث بما يمتلكه عينة البحث من معلمي المرحلة الابتدائية من معارف تخصنُ الإسعاف الأولي

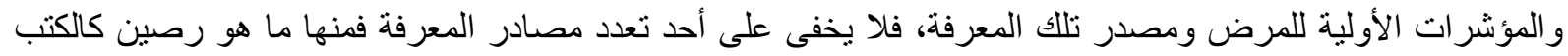

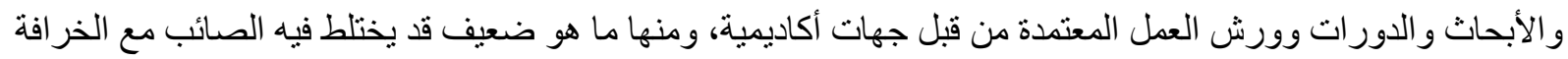

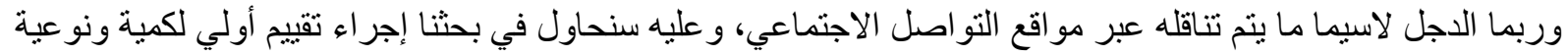

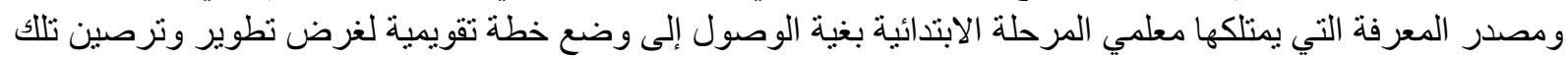

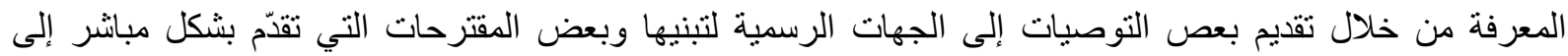

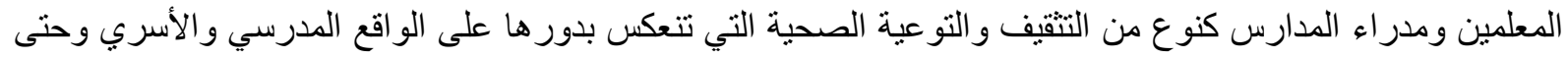

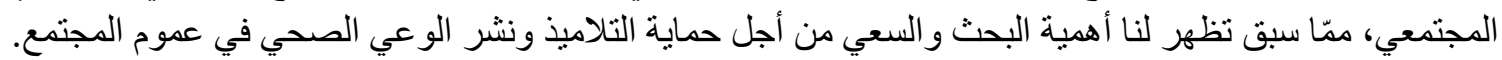

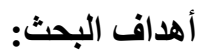

إنّ الهدف النهائي للبحث الحالي والبحوث المثبلة هو نشر ثنافة الوقاية و الكثف المبكر و الإسعاف الأولي للحد من

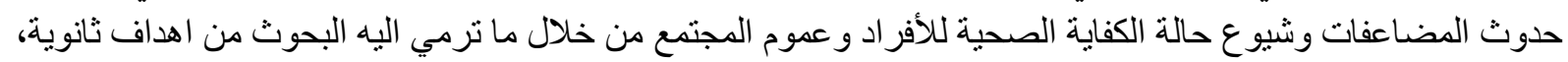
اذ يمكن للقارئ الكريم من خلال عنوان و هدف البحث العام استقر اء اهداف البحث الثنانوية وبما يلي:

ـ الهـف الاول: تقييم ما بمتلكه المعلمين من معارف تخص الإسعاف الأولي ومظاهر المرض الأولية من خلال الملاحظة اليو مية للتناميذ.

ـ الهذف الثاني: التعرّف على طبيعة ونو عية ومصدر المعلومات التي يمتلكها المعلمين. ـ الهلف الثالث: معرفة الإمكانيات المنو افرة داخل المدرسة و التي تخصُّ إجر اءعات الصحة و والسلامة و الإسعاف الأولي.

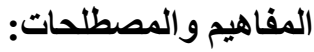

_التقييم Assessment التقييم: في اللغة هو تثمين الثيء.

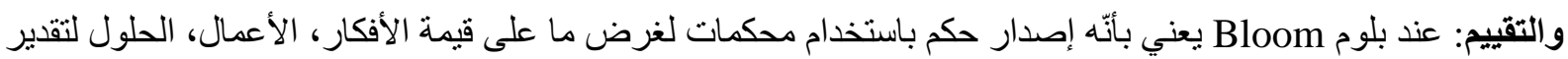

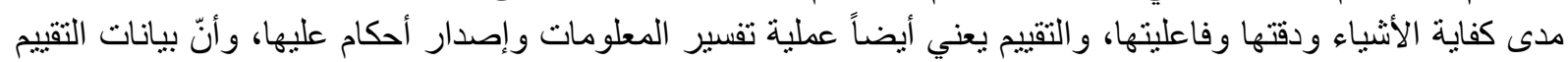

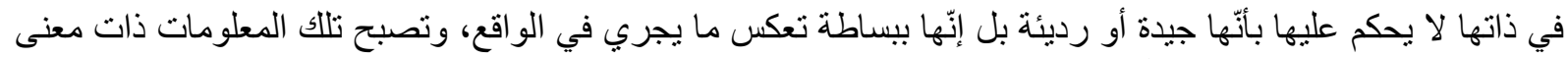

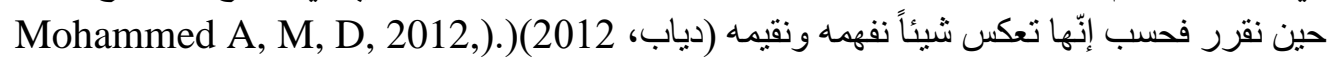

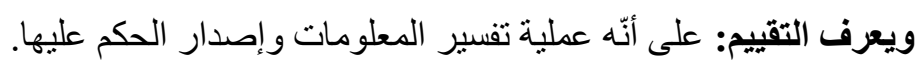

Evaluation التقويم:

التقويم: في اللغة بعني قوم الثيء؛ أي صحّحه وأز ال عنه العوج.

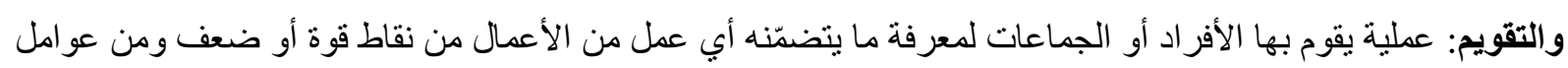

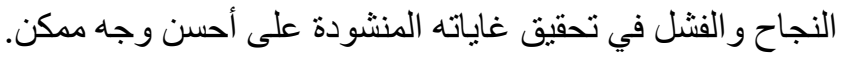

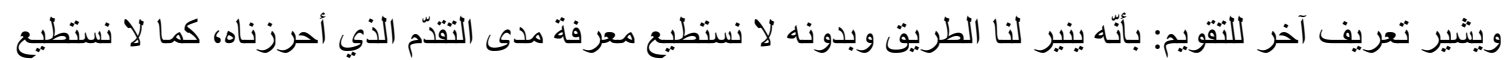

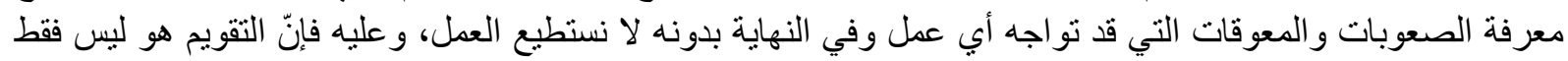

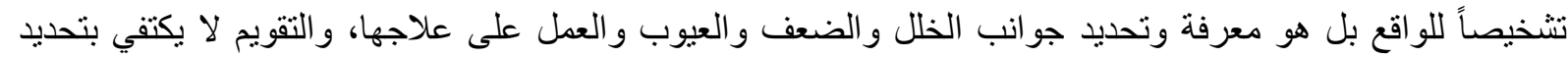

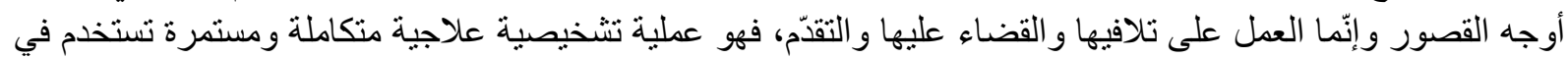
مختلف العلوم الاجتماعية، التربوية، الصحية، النفسية، الاقتصادية والفياء

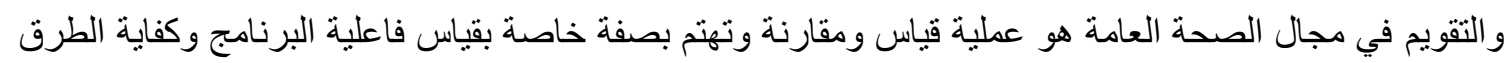

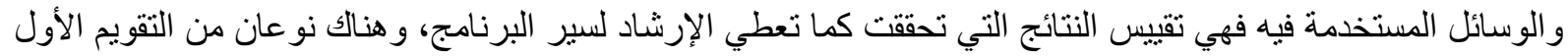
تقويم سير البرنامج وتقويم نتائجه. 


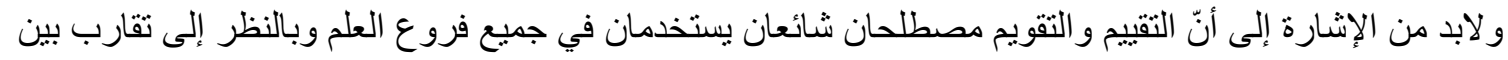

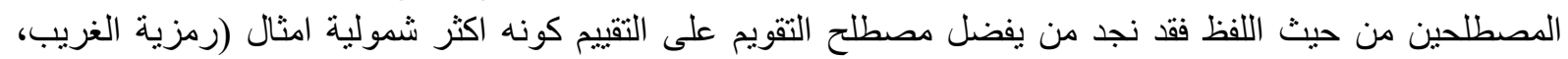

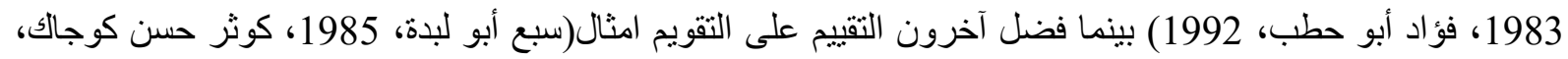

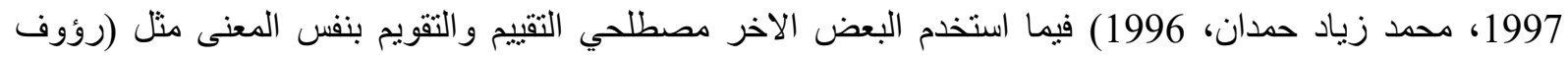
العاني، 1982) (دياب، (Mohammed A, M, D, 2012;10)(1012:10) و التقويم كهدف في سياق البحث الحالي هو إعادة النظر في أهمية وجدوى تكثثف برامج الارشاد و التتقيف الصحي

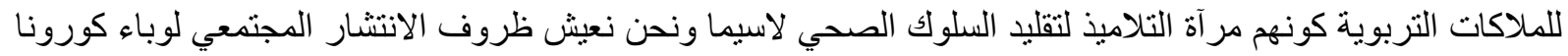
كوفيد 19 المستجد.

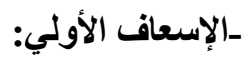

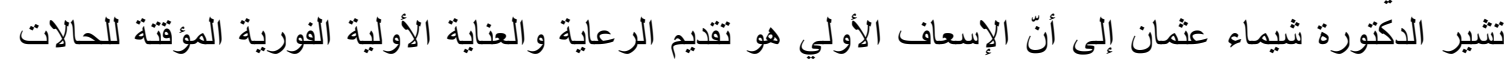

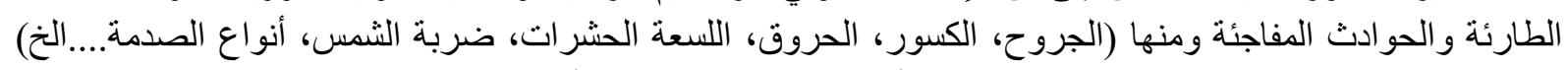

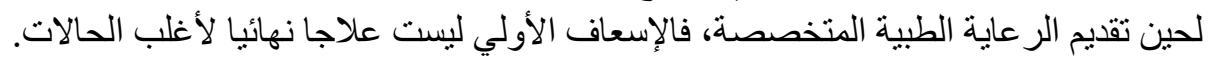

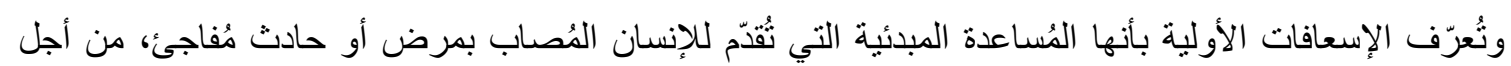

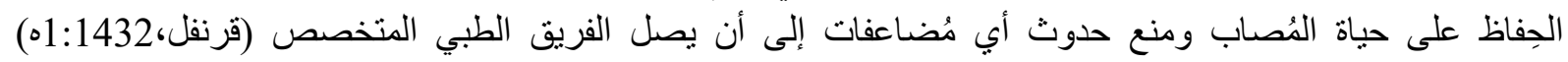
(Kurunful, A, R,1432;51)

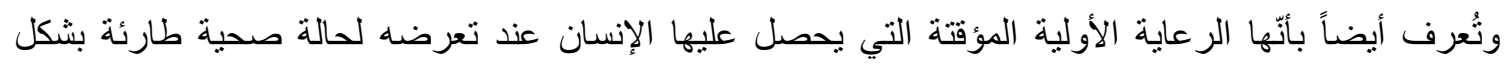

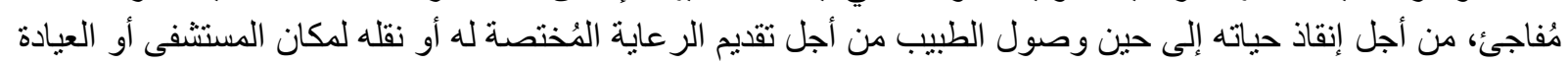

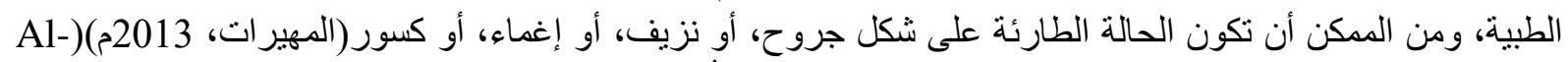

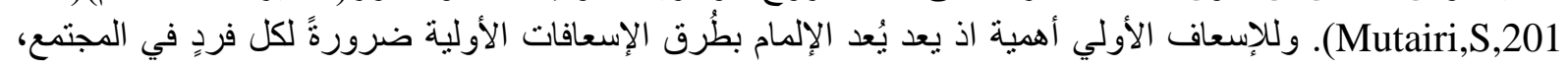

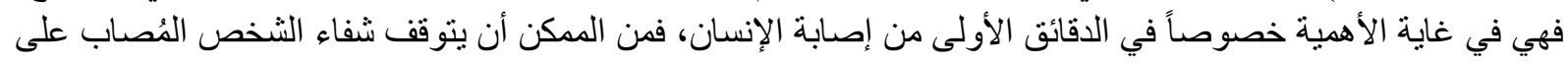

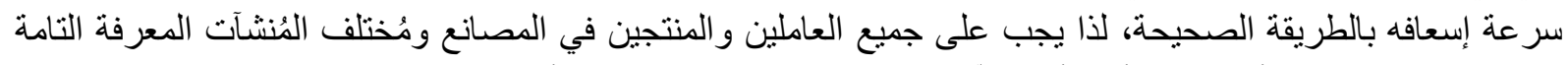

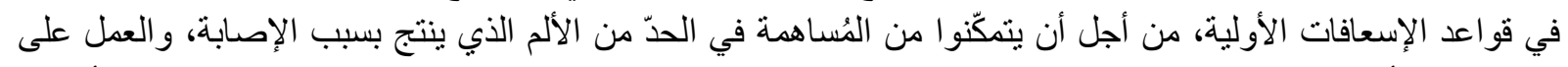

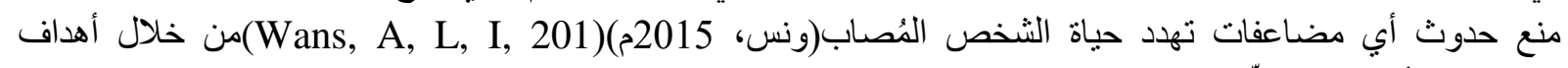

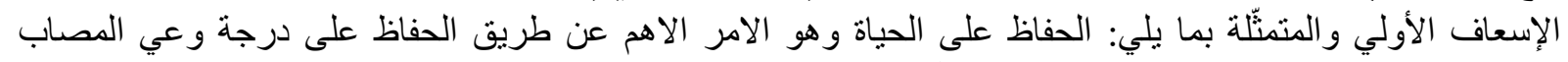

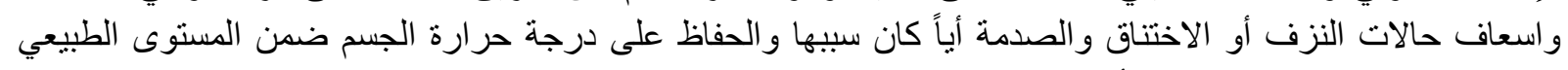

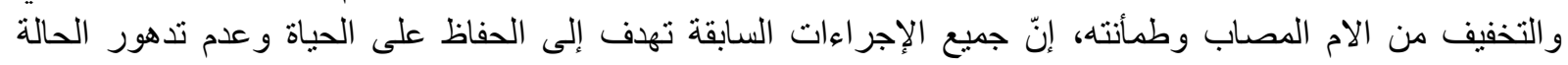
و المساهمة في تعجيل الثفاء.

ـالمرحلة الابتائية: يُعبّر المختصون عن هذه المرحلة بانها مرحلة الطفولة المتوسطة و المتأخرة والتي تمتد بين عمر 6-

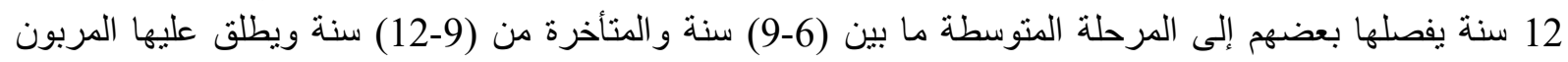

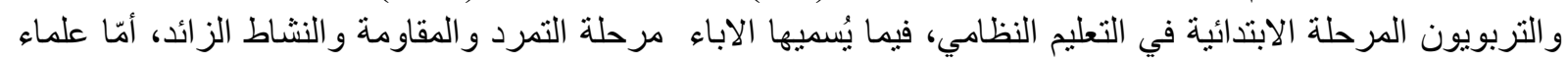

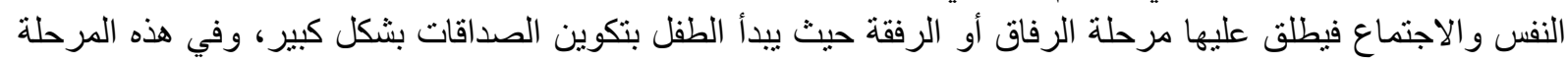

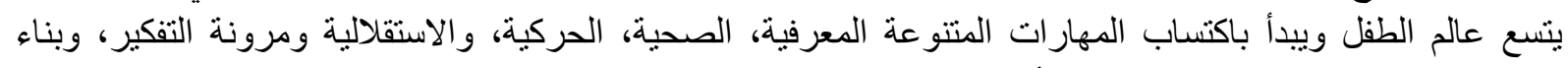

اتجاهات وسلوكيات ايجابية...الخ. (كتاب ألكتروني، 2009 (Ibrahim, Abu Qasim2009)

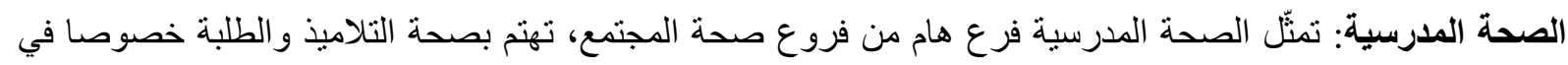

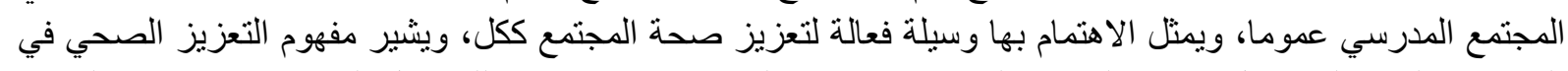

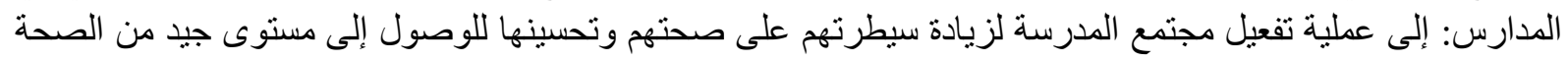

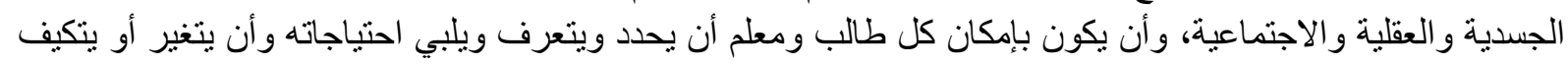

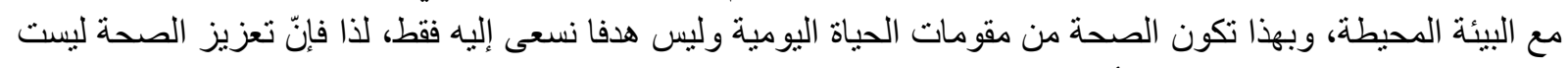

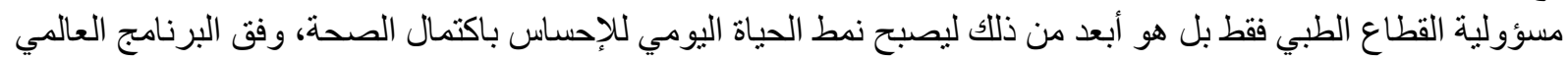
الثامل للصحة المدرسية. 
وفي تعريف آخر للصحة المدرسية هي مجموع ة المفاهيم و المبادئ والانظمة والخدمات التي تقدم لتعزيز صحة التناميذ

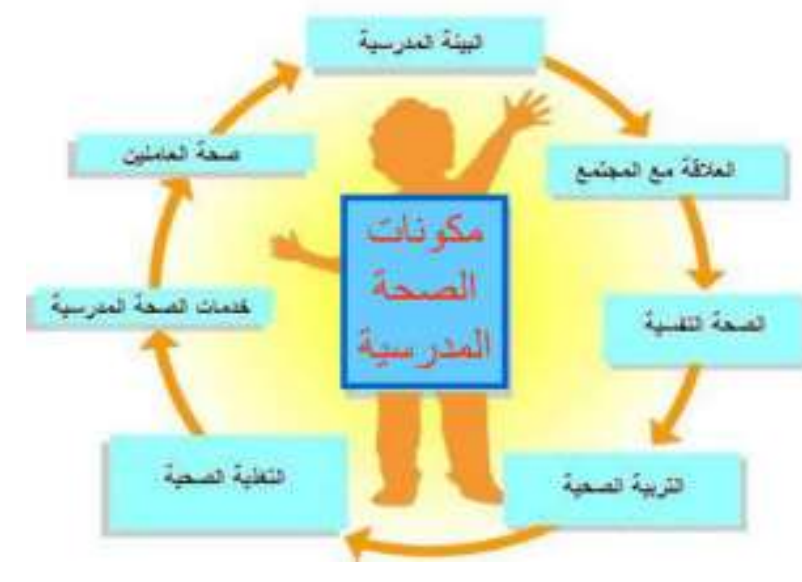
و المعلمين وعموم العاملين ضمن الطار الصحة المدرة المدرسية وبالتالي تعزيز صحة المجتمع من خلال المدارس.

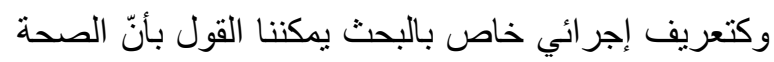

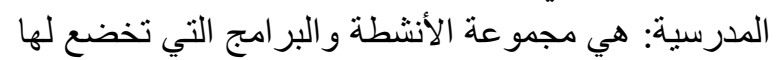

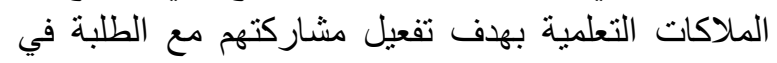

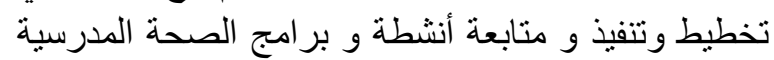
الثناملة عبر رفع مستوى الوعي الصحي و البيئي للطلبة

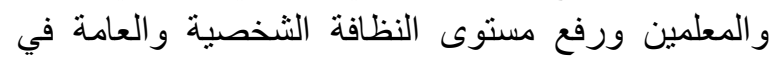

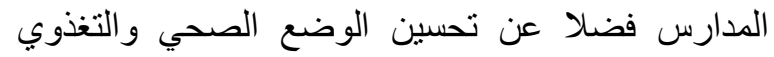

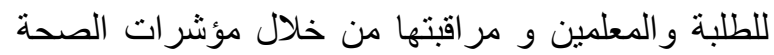
البدنية و النفسية وجودة الأداء اليومي للتناميذ و المعلمين.

مصطلحات ذات علاقة بموضوع البحث

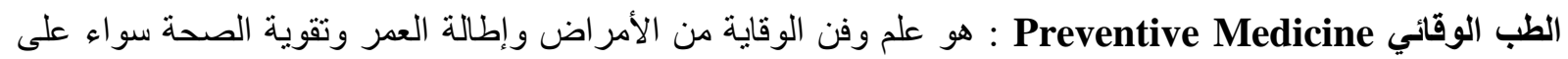

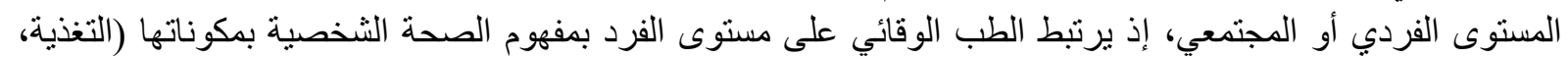

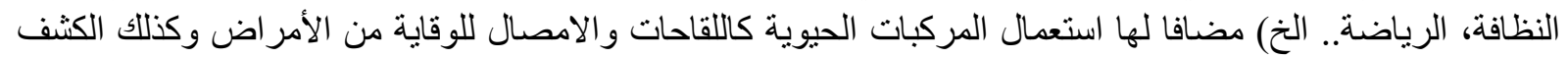

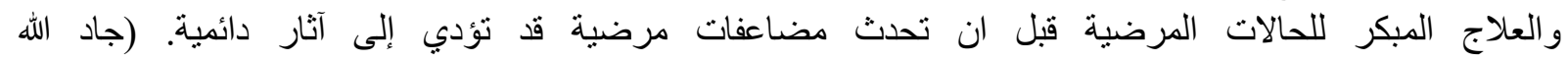

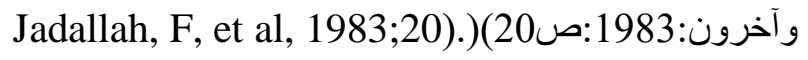
أمّا الطب الوقائي على مستوى المجتمع فهو يشبه في مفهومده العام الطب الوقائي على مستوى الفرد الا أنّه بركّز

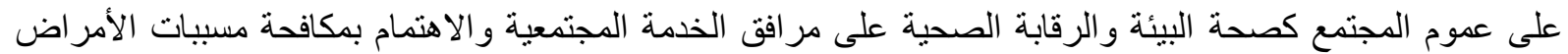

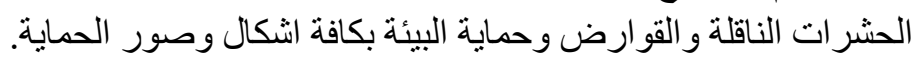

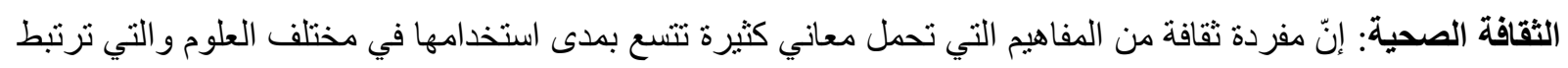
بمختلف جو انب الحياة، فلا يمكن حصر مفهوم الثنة من الثقافة في تعريف محدد.

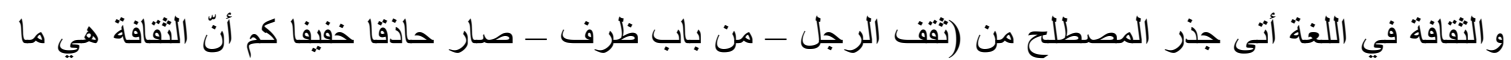

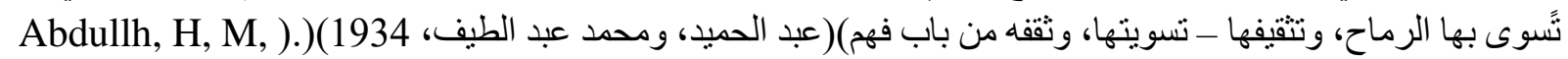
\&, Al-Sayis, M, A, 1934

و الثقافة عند رالف لنتون بانها التشكيل الخاص بالسلوك المكتسب ونتائج السلوك الذي يشترك جميع افر اد مجتمع ما

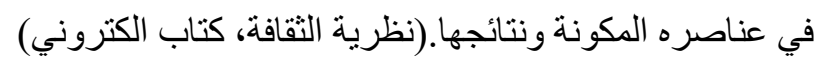

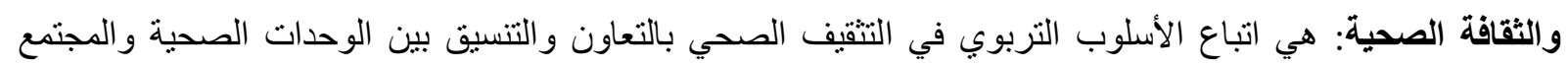

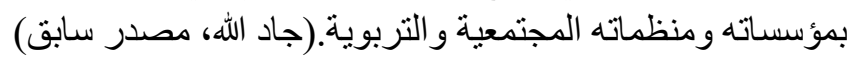

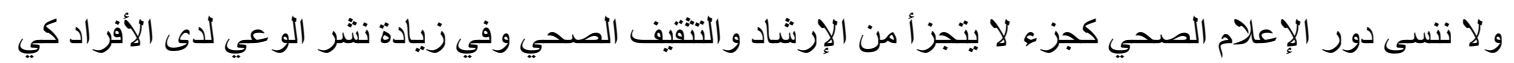

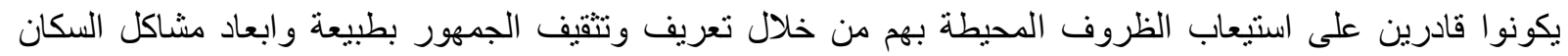
الصحية. (الثمري، 2018)(2018) Al-Shimmari, A, J و الثقافة كمفهوم اجر ائي في البحث الحالي هو كل ما يرتبط بالمعارف السلوكية الصحية التي يمتلكها معلمي المرحلة

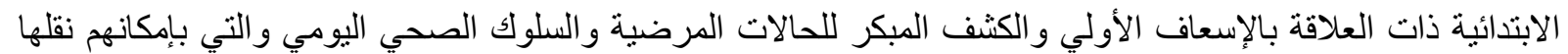
إلى التلاميذ. 
1- دراسة بعنوان(واقع البيئة المدرسية بولاية سكسيدة موسم 2017-2018، دراسة ميدانية على عينة من المدارس الابتدائية قريشي الياس وبلعربي زبيدة)

الملخص Numéro 3, Pages 66-75, 7 Volume تعد فترة الطفولة مرحلة هامة في حياة الإنسان اذ ينمو المتمدرس جسمبا وعقلبا، وفي هذه المرحلة يكون الطفل اكثر

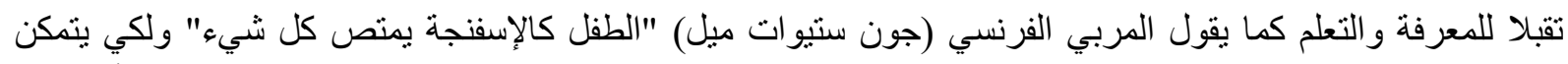

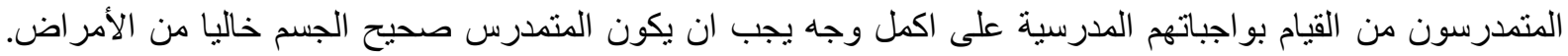

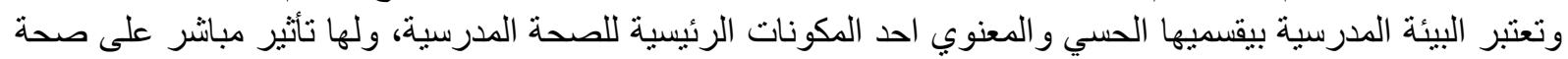

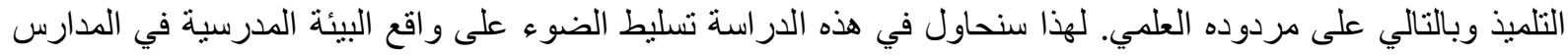

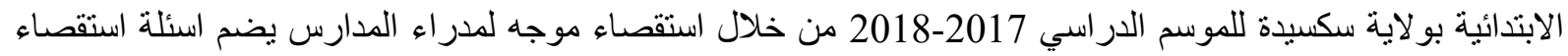

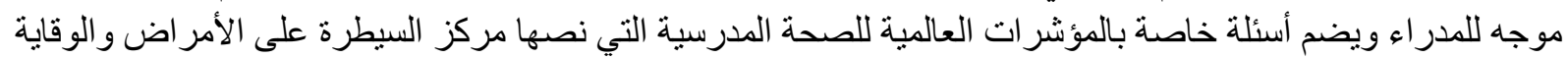
منها (CDC) أطلانطا عام 2014.

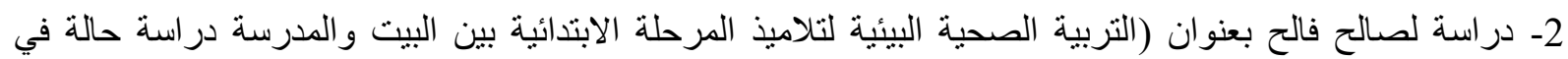
مدارس ولاية الوادي 2007-2008) حيث دارت الثاري الثكالية الدراسة حول مدى قدرة المعلمين مي المرحلة الابتدائية لاختبار

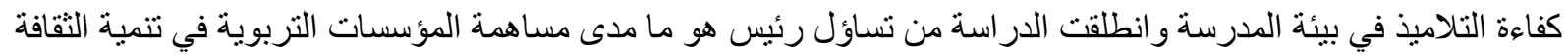

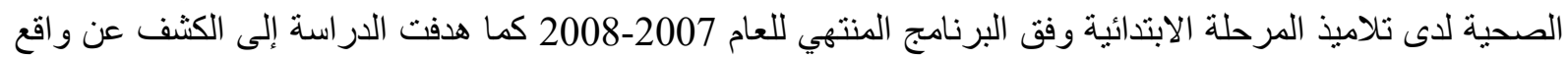

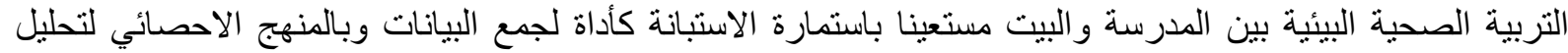

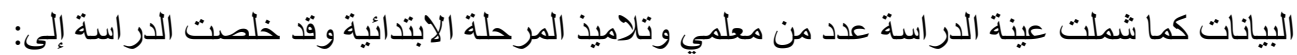

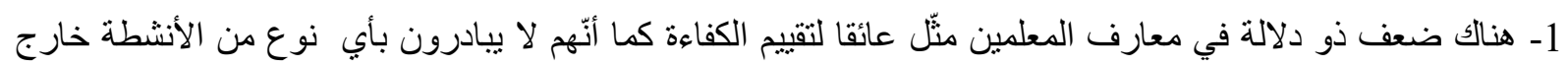

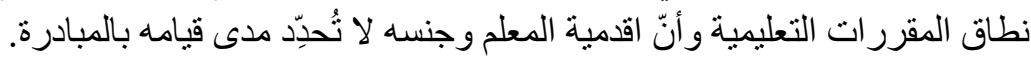

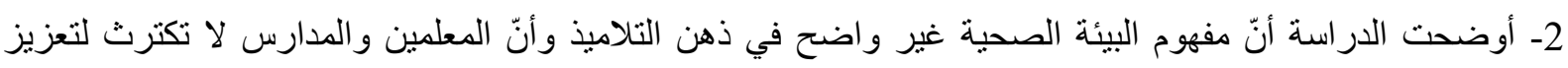
السلوك الصحي و لا تزرع روح التنافس وتقليد الممارسات الصحية وتتميتها وأنّ هناك قطيعة بين البيت و المدرسة في تنمية ذلك. وأخير أ نمّ تقديم مجمو عة من تروع التوصيات منها:

تخصيص دور ات للمعلمين في مجال الصحة و السلامة داخل البيئة المدرسية

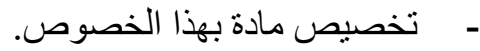

- - الاهتمام بالوسائل التوضيحية الحديثة التي تمكن المعلمين و التلاميذ من تطوير ثقافتهم ومهار اتهم الصحية.

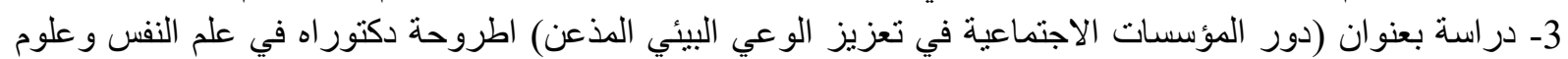

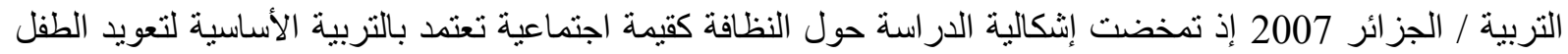

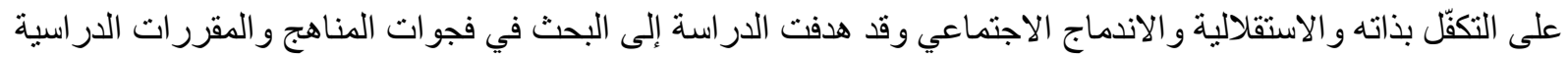

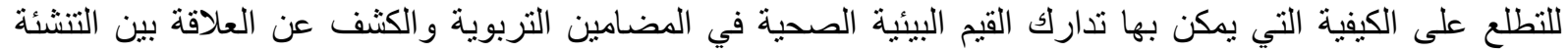

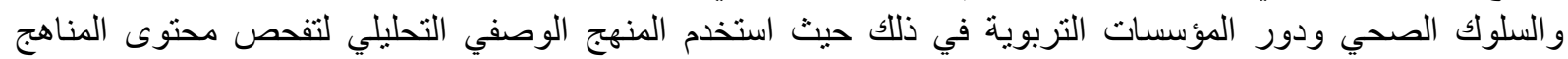

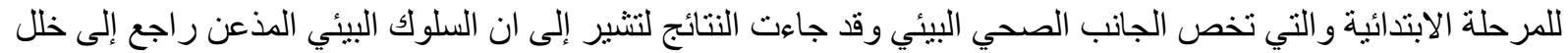

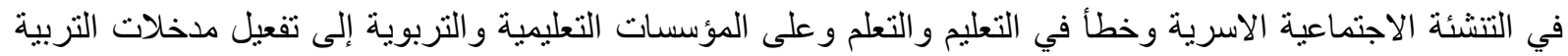

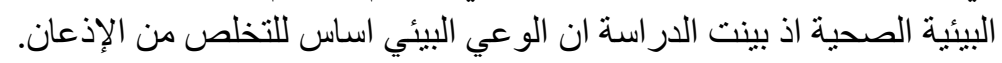

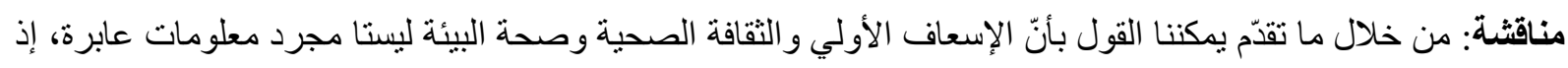

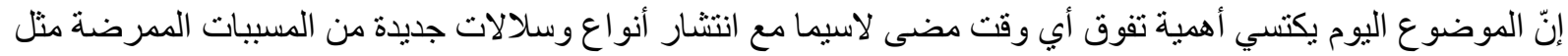

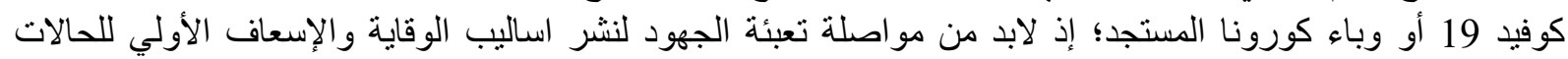

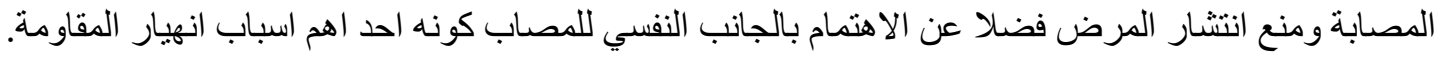


لقد واجهت وتو اجه البشرية الكثير من الحوادث و الكوارث و انتشار الأوبئة والأمر اض الأمر الذي تطلب من الإنسان

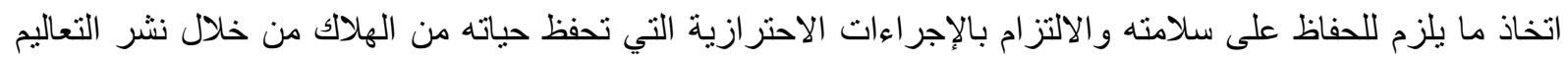

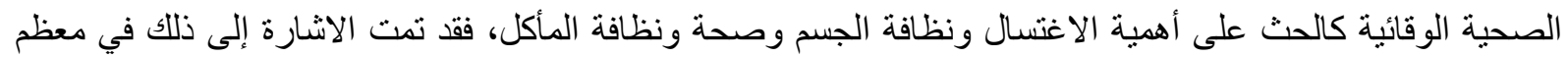

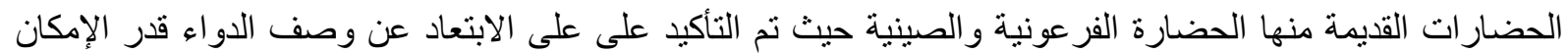

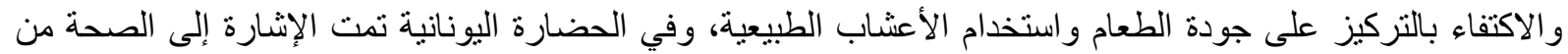

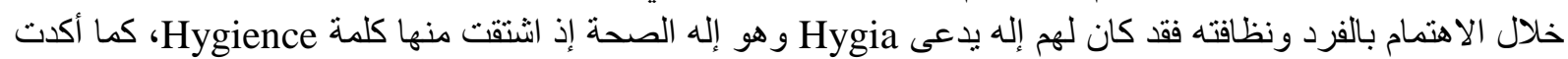

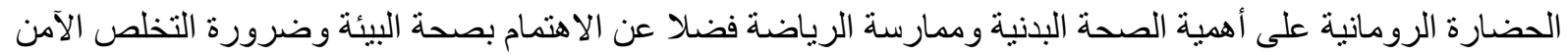

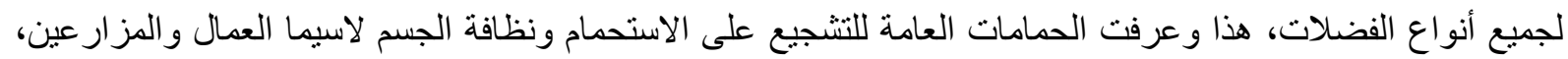

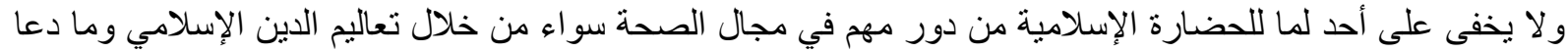

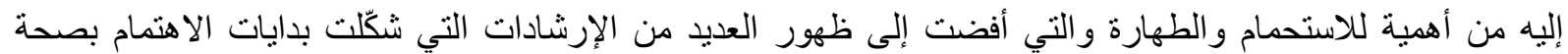

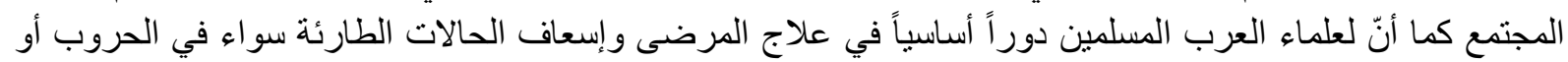

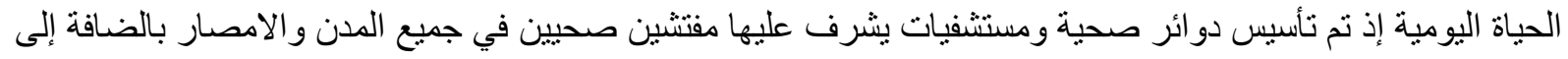

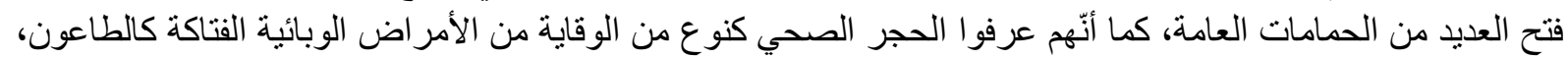

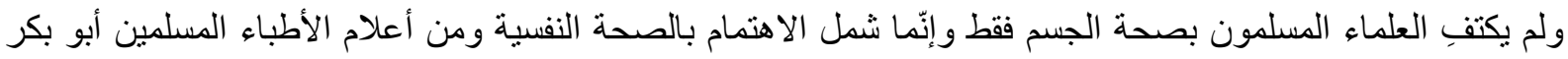

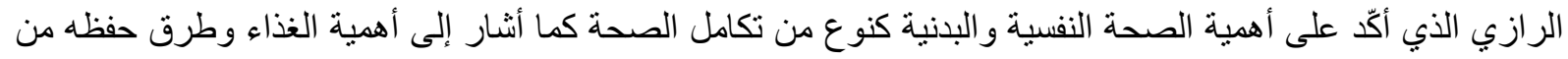

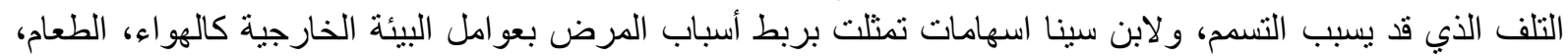

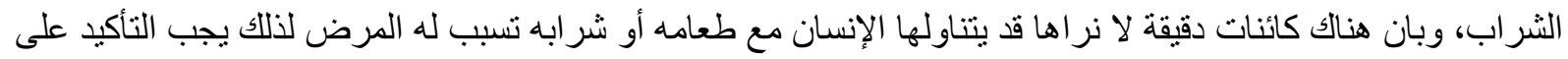

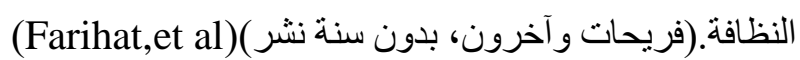

لقد شهر العصر الحديث تطوّراً كبيراً على مستوى التكنلوجيا الطبية سواء التشخيصية كانت أم التأهيلية والعلاجية

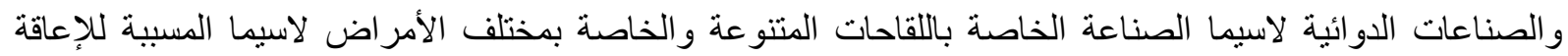

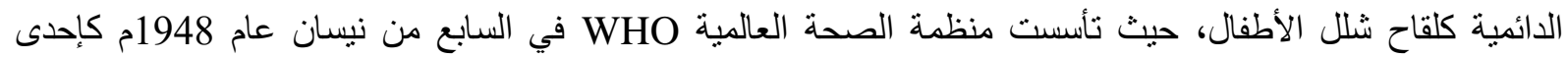

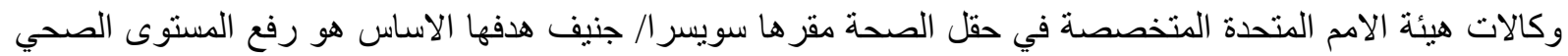

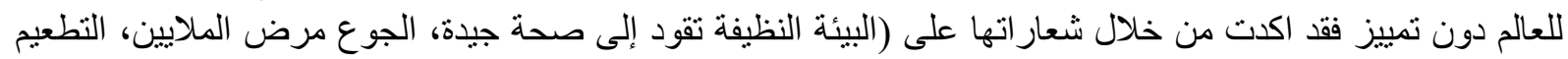

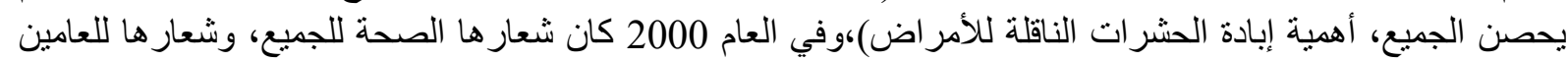

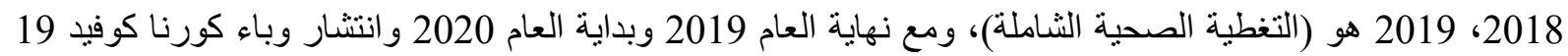

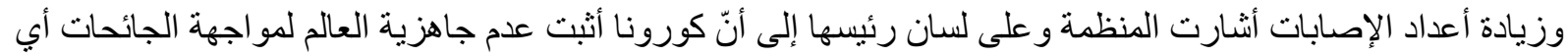

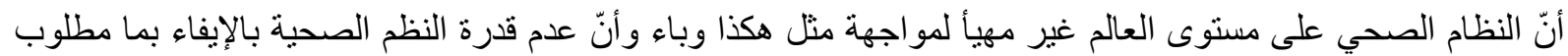

مدعاة للقلق.

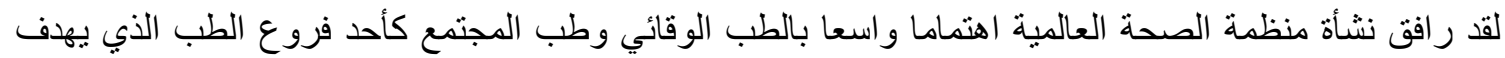

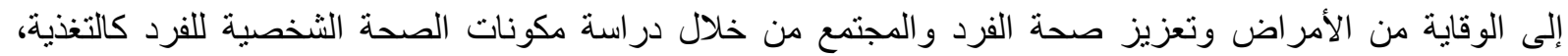

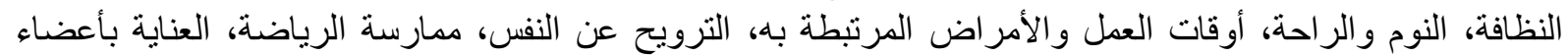

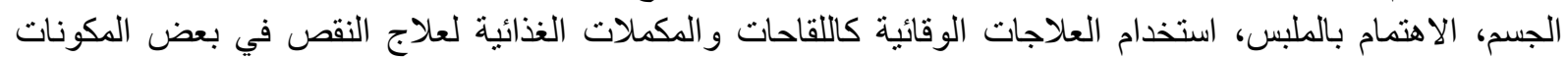

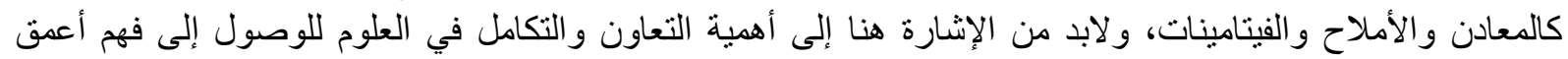

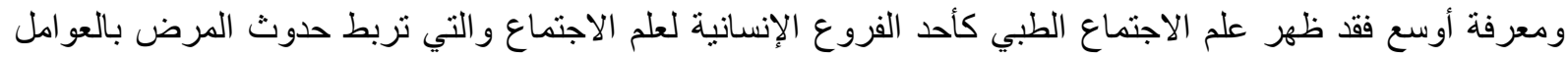

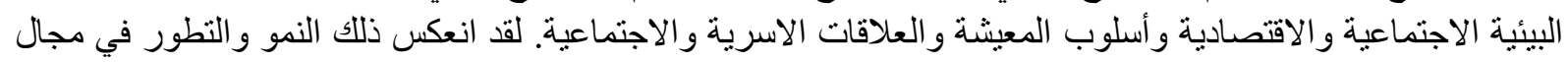

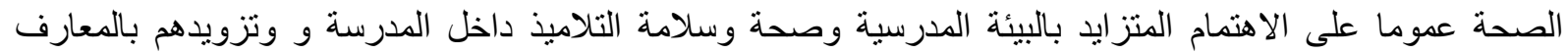

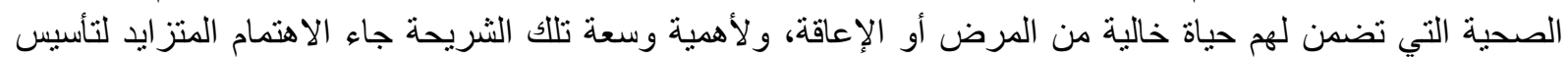

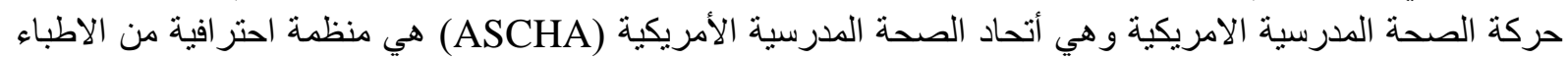

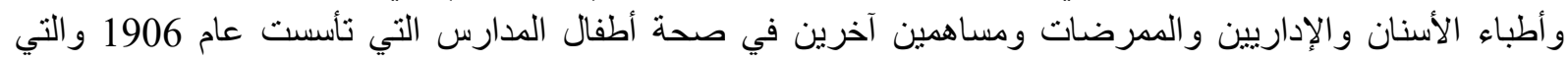

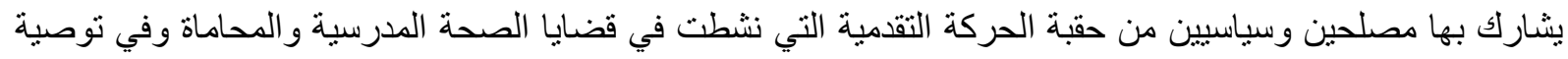

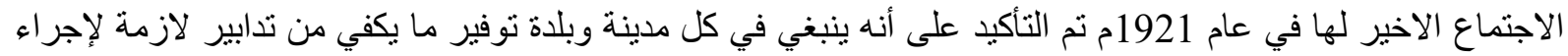

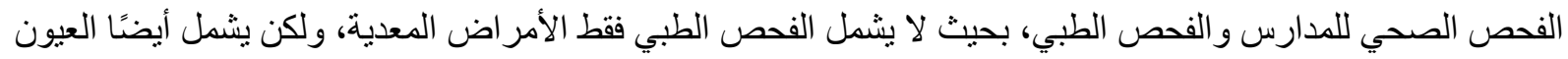

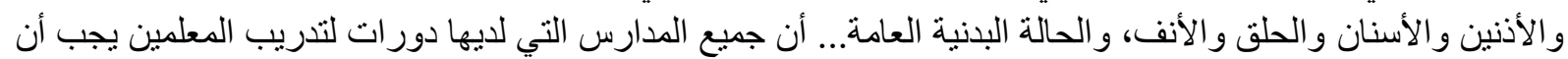




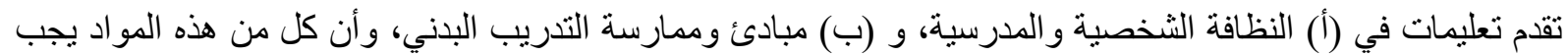

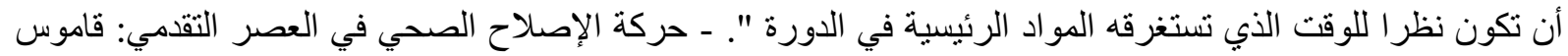

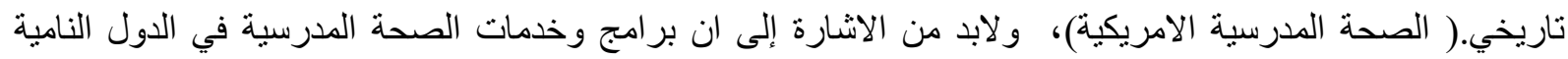

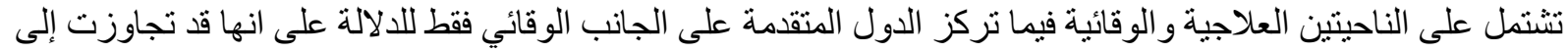

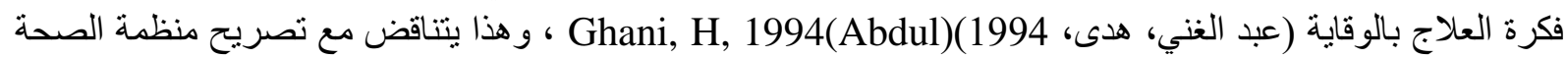
العالمية WHO حول فثل الانظمة الصحية في العالم بأسره في ومواجهة كورونا، حيث لم تفي الخدمات العلاجية

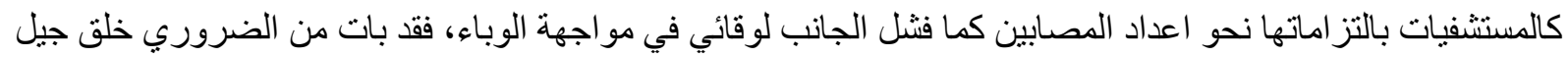

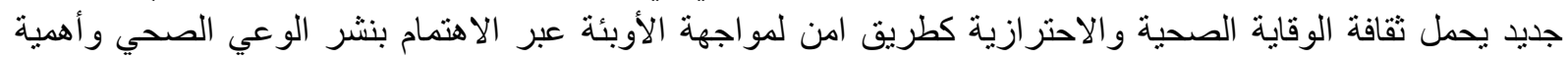

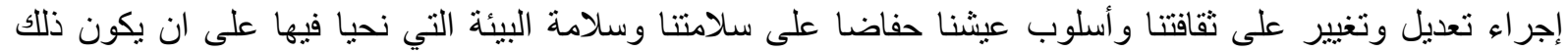
طو اعية وكأسلوب حياة وليس في اوقات انتين وانتار الأمر اض و الأوبئة.

الجانب الميداني: (منهجية و عينة و أدوات البحث، عرض النتائج والاستنتاجات، التوصيات و المقترحات، المصادر).

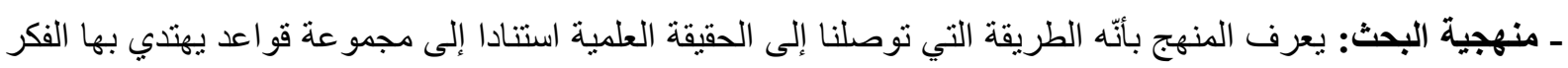

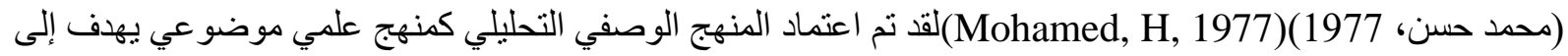
الحصول على المعلومات وتحليلها احصائيا باستخدام النسبة المئوية. ـ عينة البحث: لقد نمّ جمع معلومات البحث من عينة قو امها 50 معلم ومعلمة وكانت العينة عشو ائية لكنها محددة بخصائص كونهم من ضمن الملاكات التعليمية للمرحلة الابتدائية. ـ أدوات البحث: لقد نمّ استخدام أسلوب المقابلة واستمارة الاستبانة كأداة ساندة لعملية جمع البيانات حيث تم صباغة أسئلة

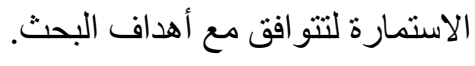
-عرض نتائج البحث واستنتاجاته: جدول رقم (1) توزيع فئات عينة البحث

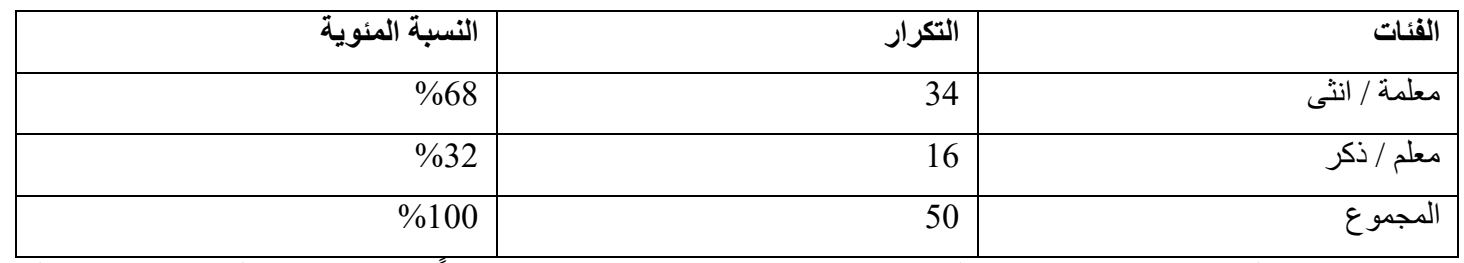

يبين فئات العينة وتوزيعها حسب النوع 34 بنسبة 68\% إناثا، و16 ذكوراً بنسبة 32\% ليكون مجموع العينة 50 \% ونسبة 100\% الجدول رقم (2) خاص بالتحصبل الدر اسي لفئات العينة

\begin{tabular}{|c|c|c|c|}
\hline النسبة \% & معلمة & معلم & التحصيل العلمي \\
\hline$\% 38$ & 11 معلم جامعي & 8 معلم جامعي & بكالوريوس \\
\hline$\% 62$ & 31 & - & دبلوم \\
\hline$\% 100$ & 50 & & المجموع \\
\hline
\end{tabular}

يشير الجدول إلى توزيع فئات العينة حسب التحصيل العلمي حيث كان مجموع المعلمين من حملة شهادة

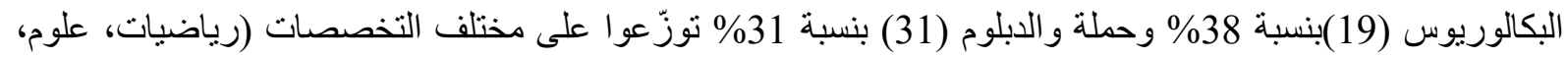
لغة عربية، إسلامية، لغة انكليزية، فيزياء، علوم حياة) 
جدول رقم (3) يوضح إجابات المبحوثين عن السؤال (هل لديك معرفة بمؤشرات المرض الظاهرية التي يمكن قياسها؟

\begin{tabular}{|c|c|c|}
\hline النسبة\%\% & التكرارات & الإجابة \\
\hline$\% 100$ & 50 & نعم \\
\hline$\% 0$ & - & $y$ \\
\hline$\% 100$ & 50 & المجموع \\
\hline
\end{tabular}

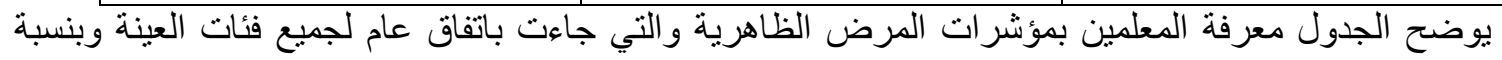

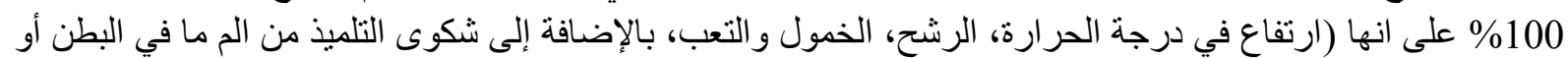

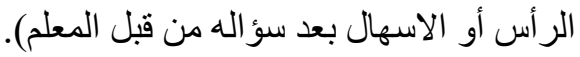
جدول رقم (4) يبين إجابات المبحوثين على السؤال (ماهي العلامات الحيوية التي تحتل الاولوية لقياسها في حالات الإسعاف الأولي و المرض؟ (4) بلجن

\begin{tabular}{|c|c|c|}
\hline النسبة\% & التكرار & 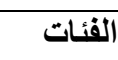 \\
\hline$\% 100$ & 50 & 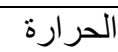 \\
\hline$\% 100$ & 50 & التتفس \\
\hline$\% 12$ & 6 & 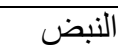 \\
\hline$\% 32$ & 16 باستخدام اجهزة القباس الالكترونبة & 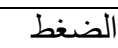 \\
\hline المجموع يمثل اكثر من إجابة للمبحوثين & 122 & المجموع \\
\hline
\end{tabular}

يييّن الجدول تسلسل أولوية العلامة الحيوية الو اجب قياسها من وجهة نظر المبحوثين و التي تبدأ بالحرارة إذ كان

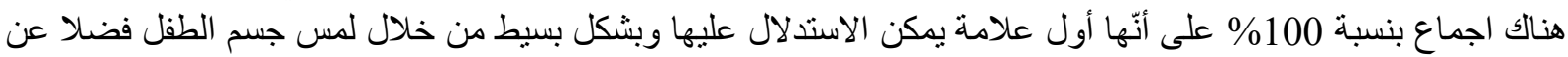
كونها علامة شبه عامة لوجود المرض سواء ارتفاعها (سخونة الجسم) أو انخفاضها (برودة الجسم) يليها سرعة التها أو بطئ

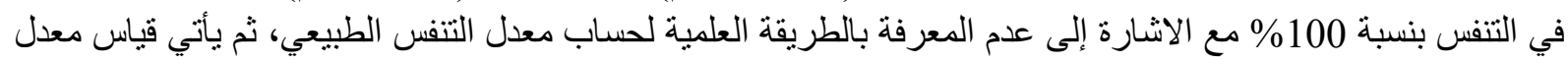
النبض و الضغط كعلامتين تحتاجان إلى معرفة وخبرة علمية و عملية لقياسهما بنسبة 12\% للنبض و 32\% لضغنط الدم و وهذا ما لا يمتلكه معظم المبحوثين وان كان البعض منهم لديه معرفة بسيطة لكنها غير دقيقة، حيث تم تقييم تللك المعرفة من خلمة خلال

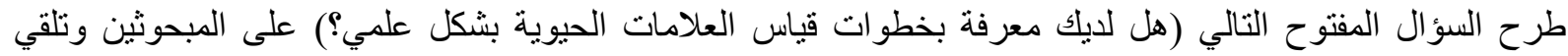
الإجابة عن طريق شرح خطوات ال و اداة إجر اء قياس العلامة الحيوية.

جدول رقم(5) يبين مشاركة المبحوثين في دورات الإسعاف و الر عاية الصحية للحالات الطارئة.

\begin{tabular}{|c|c|c|}
\hline النسبة \% & 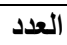 & هل شاركت في دورة للإسعاف الأولي ؟ \\
\hline$\% 12$ & 6 & نعم \\
\hline$\% 88$ & 44 & $\gamma$ \\
\hline$\% 100$ & 50 & 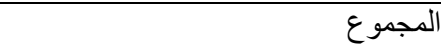 \\
\hline
\end{tabular}

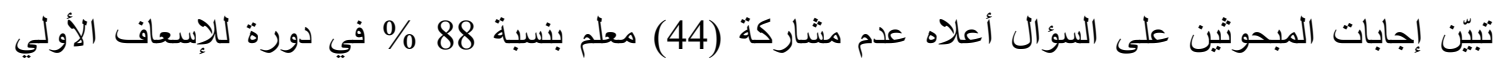

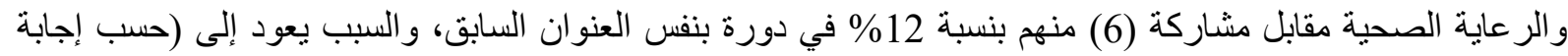
المبحوثين على السؤ ال المفتوح ألا ترغب بالحصول على معلومات عن الإسعاف الأولي والرعائ الرعاية الصحية المدرسية ؟)

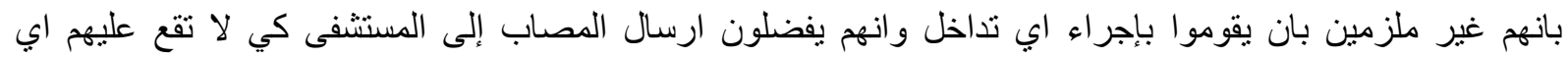

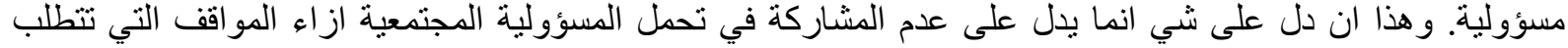

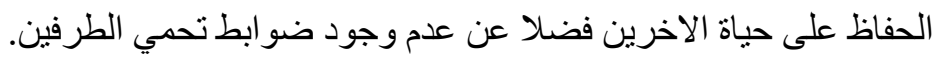
جدول رقم (6) يوضح إجابات المبحوثين على السؤال هل تعلم ان ما تحصيّل عليه من معلومات عن الإنس الإسعاف الأولي قد

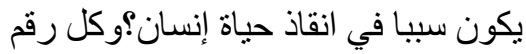




\begin{tabular}{|c|c|c|}
\hline النسبة \% & العدد & 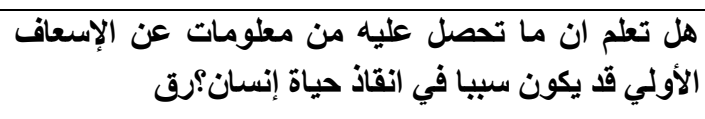 \\
\hline$\% 100$ & 50 & نعم \\
\hline صفر & صفر & $y$ \\
\hline$\% 100$ & 50 & المجموع \\
\hline
\end{tabular}

تؤكد إجابة جميع المبحوثين البالغ عددهم 50 وبنسبة 100\%على علمهم بان المعلومات عن الإسعاف الأولي من الإن

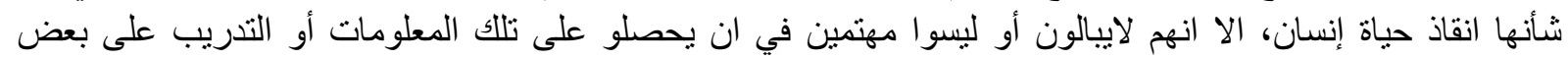

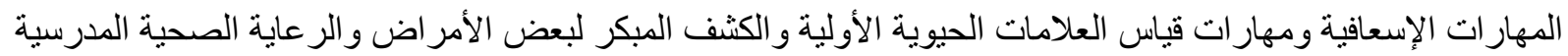

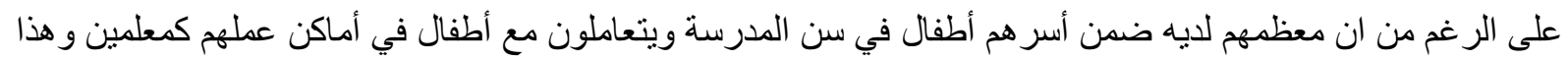

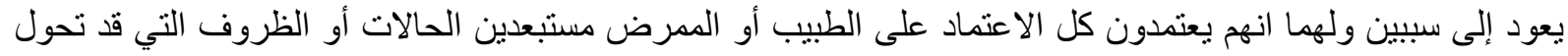

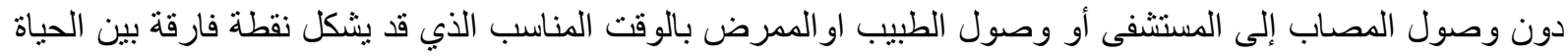

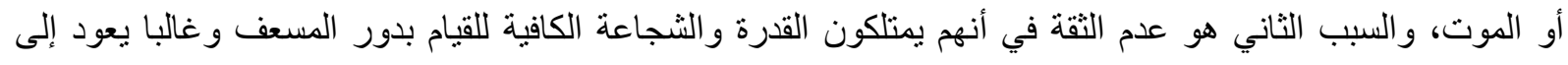

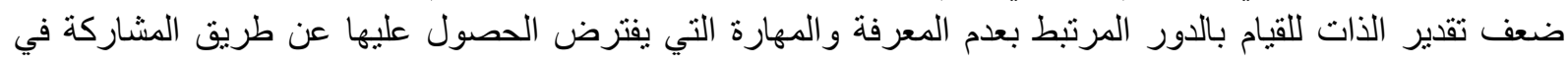
دورات وورش التدريب النظري و التطبيقي.

جدول رقم(7) يوضح إجابات المبحوثين حول وجود صندوق للاسعاف الأولي في المدرسة ؟

\begin{tabular}{|c|c|c|}
\hline النسبة \% & 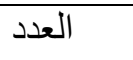 & هل يوجد صندوق للاسعاف الأولي في المدرسة ؟ \\
\hline$\% 42$ & 21 & نعم \\
\hline$\% 30$ & 15 & $y$ \\
\hline$\% 28$ & 14 & ل ل الا اعلم \\
\hline$\% 100$ & 50 & 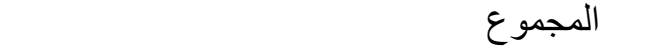 \\
\hline
\end{tabular}

يعكس الجدول أعلاه إجابات المبحوثين حول معرفتهم بوجود صندوق للاسعاف الأولي من عدمه وقد كانت

الإجابات

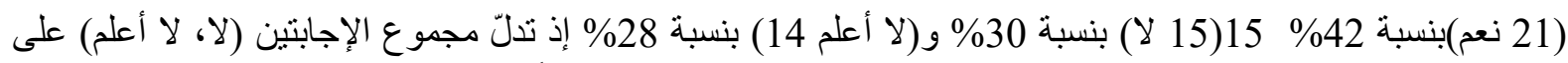

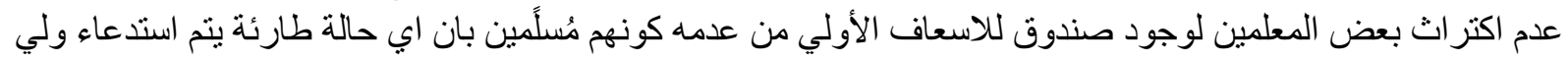
امر الطفل وارساله إلى اقرب مركز صحي اومستشفى إلى المدرسة دون اتخاذ اي إجر اء خاص بأ بالإسعافات الأولية.

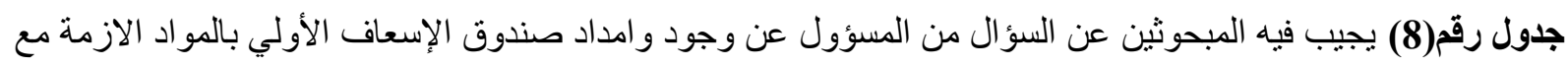
متابعة مدى صلاحيتها ؟

\begin{tabular}{|c|c|c|}
\hline النسبة \% & عدد الإجابات & بالمواد الازمة من مع متابعة مدى صداد صناحيتها الإسعاف الأولي \\
\hline$\% 19$ & 38 & الإلدارة \\
\hline$\% 20.5$ & 41 & المعاونين \\
\hline$\% 13.5$ & 27 & معلم العلوم \\
\hline$\% 9$ & 18 & مرشد الصف \\
\hline & 114 & المجموع الإجابات \\
\hline
\end{tabular}

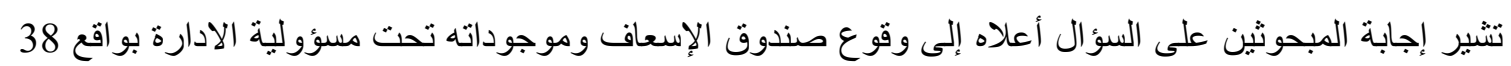

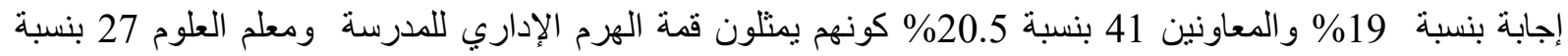

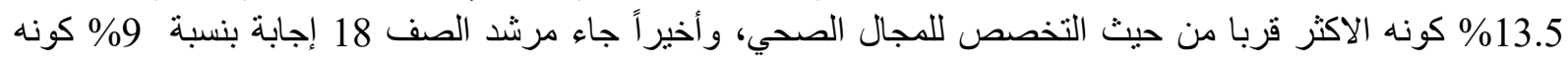


المسؤول عن مر اقبة التلاميذ لاسيما أوقات الاستراحة بين الدروس، و لابد من الإشارة إلى أنّ مجموع الإجابات تجاوز عدد العينة لاختيار هم اكثر من إجابة.

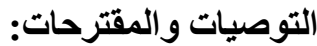

1- التأكيد على أهم هدف للإسعاف الأولي في إنقاذ حياة المصاب من خلال تدريب وتأهيل الأفراد عموما من غير التهاب

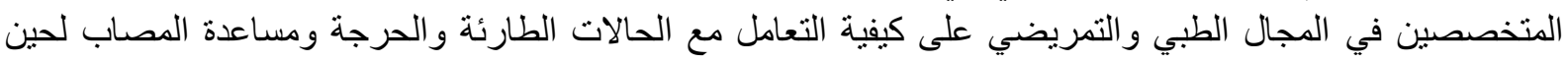
توفر الخدمة الطبية اللازمة. 2- العمل بكل جهد على تنفيذ بنود البرنامج الوطني للصحة المدرسية باعتباره احد الاولويات الوطنية التي تهتم بشريحة

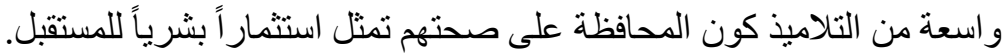

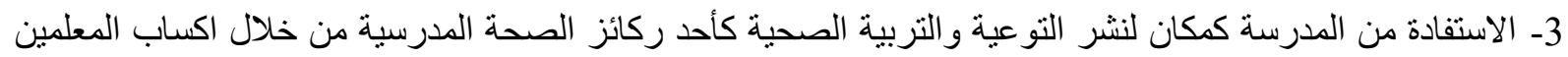
و التلاميذ العادات و السلوك الصحي السليم في الاحو ال الاعتيادية أو في اوقات التهات النتشار الأوبئة.

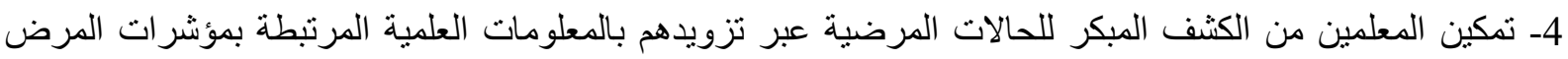

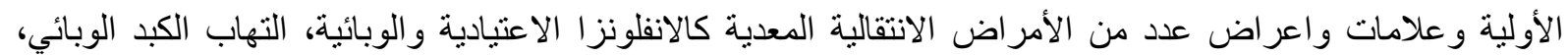

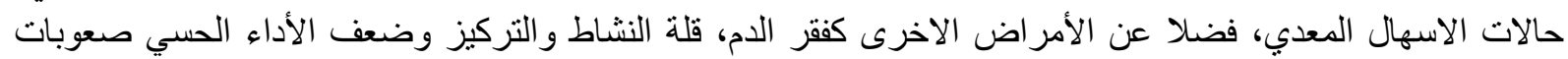
التعلم النمائية و غير ها من المشاكل النفسجسية ونسية وتربوية. 5ـ الاستفادة من ما يتلقاه التلاميذ من عادات صحية سليمة وتحويله إلى سلوك يونة يومي ونقله إلى الاسرة و المجتمع في تحقيق عملية تو عية مجتمعية شاملة. 6- تزويد العاملين في المجال التربوي بالمعارف المرتبطة بالسلوك الصحي السليم وسبل إجر اء تقييم دوري لصحئ الصحة التلاميذ

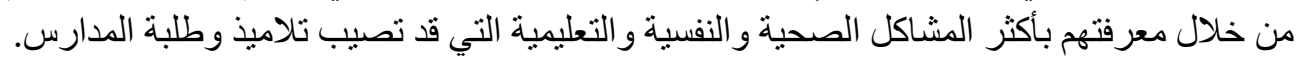
7ـ العمل على ضرورة تطبيق وانجاح برامج الصحة المدرسية بغية التحول مستقبلا من النمط العلاجي السائد إلى النمط النها

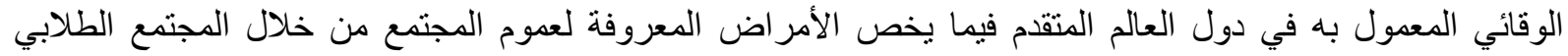

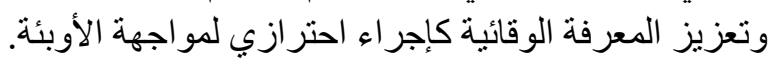

8- السعي إلى تخصيص مكان مناسب لإجر اء الإسعاف الأولي مزود بالمستلزمات الاساسية ويمكن تشكيل فريق عمل كلئ مدرب من قبل عدد من معلمي المدرسة للقيام بذللك.

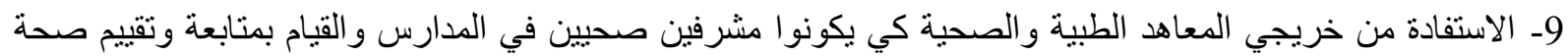
التلاميذ وتزويد الملاكات التعليمية بالمعارف من خلال عقد الورش والمان الندوات وفق آخر المستجدات. 
أبو الرب، صلاح، 1995، مقدمة في صحة المجتمع، القاهرة، دار الفلاح للنشر.

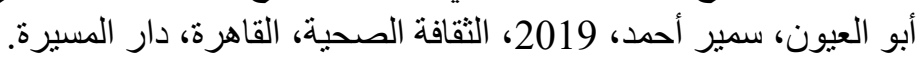

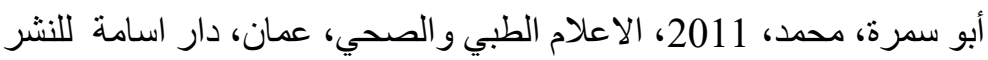

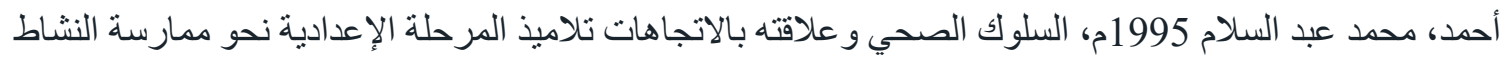

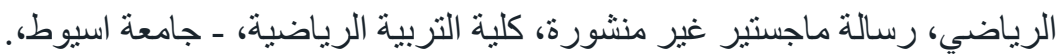

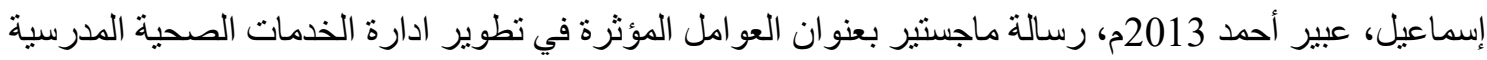

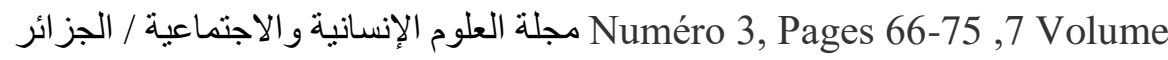
جاد الله، فوزي، واخرون، 1983 الصحة العامة والخدمات الصحية، العر اق، دار الحرية للطباعة.

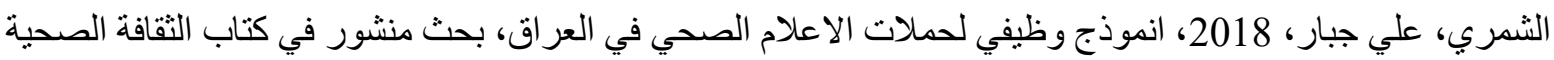
و العو امل الاجتماعية والنفسية المؤثرة في الصحة و المرض، العراف العاق - مؤسسة بيت الحكمة.

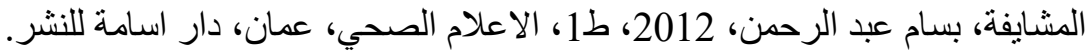
المطيري، شنوف بن مقعد بن ردن، 2013م، رسالة ماجستير فاعلية الادارة المدرسية في المانية المحافظة على الامن و السلامة

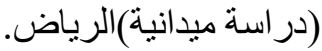

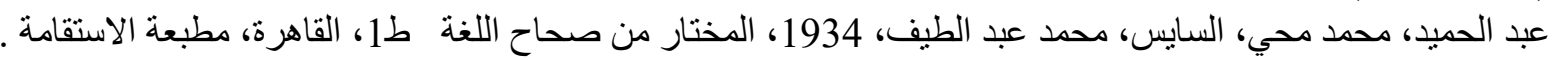

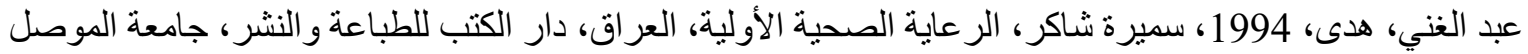

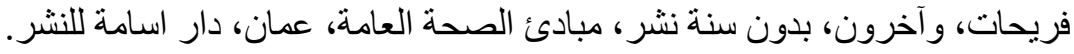

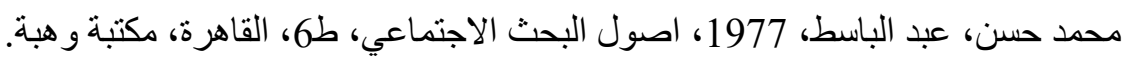

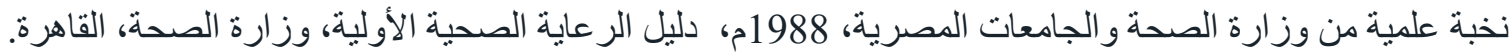

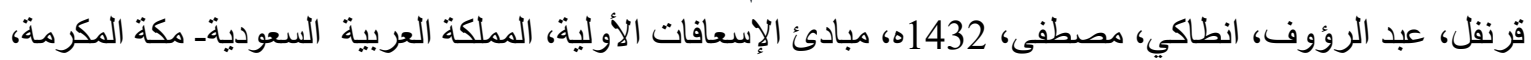

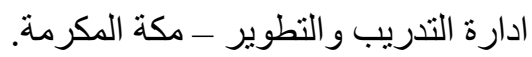

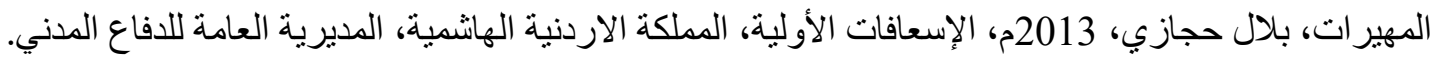

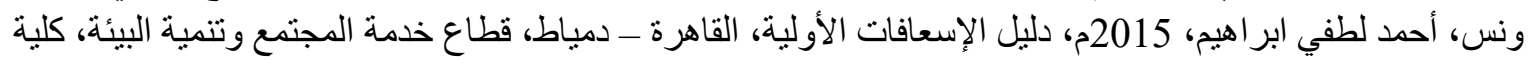

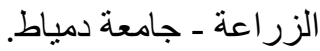




\section{مواقع إلكترونية:}

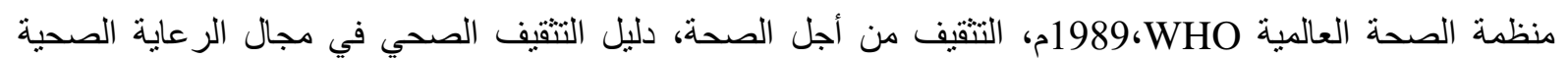
الأولية.

ابراهيم، أبو القاسم، فايز عبد المقصود شكر، امانِ محمد سعيد، الصحة المدرسية، كتاب

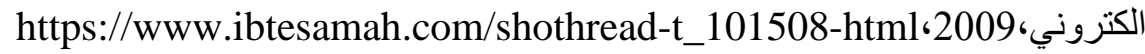

I تعريف الصحة المدرسية l الصحة المدرسية الأمريكي] l النصWHO : كورونا أثبت عدم جاهزية العالم لمواجهة الجائحات السبت 19 سبتمبر 2020 https://www.okaz.com.sa/variety/na/204160500:35

https://ar.wikipedia.org/wiki/\%D8\%A7\%D9\%84\%D8\%B5\%D8\%AD\%D8\%A9 \%D8\%A7\% D9\%84\%D9\%85\%D8\%AF\%D8\%B1\%D8\%B3\%D9\%8A\%D8\%A9 \%D8\%A7\%D9\%84\%D

8\%A3\%D9\%85\%D8\%B1\%D9\%8A\%D9\%83\%D9\%8A\%D8\%A9

https://e3arabi.com/health/\% D9\%85\% D9\% 83\% D9\%88\% D9\% 86\% D8\%A7\% D8\%A A-\%D8\%A7\%D9\%84\%D8\%B5\%D8\%AD\%D8\%A91\%D8\%A7\%D9\%84\%D9\%85\%D8\%AF\%D8\%B1\%D8\%B3\%D9\%8A\%D8\%A9 ودر اسة الباحث / علي إسماعيل الجاف البرنامج الوطني للصحة المدرسية/ العر اق 2012

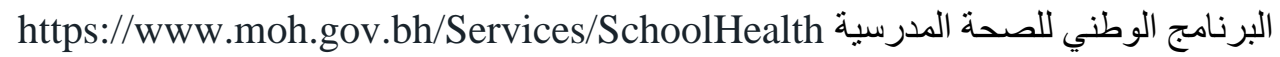

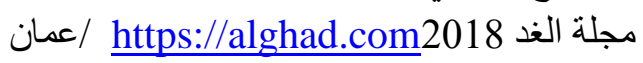
أمين الجمال، ووجيه السباعي - دبي lhttps://www.emaratalyoum.com/local-section/health/2020-08-22-1.1389533 التاريخ: 22 أغسطس 2020 